\title{
PERCEPÇÃO AMBIENTAL DAS COMUNIDADES AO ENTORNO DO PARQUE ESTADUAL DA LAGOA DO AÇU/RJ.
}

\author{
K.P.DOS SANTOS ${ }^{1}$ E V.P.S.DE OLIVEIRA ${ }^{2}$ \\ Universidade Federal do Rio de Janeiro ${ }^{1}$, Instituto Federal Fluminense ${ }^{2}$ \\ ORCID ID: https://orcid.org/0000-0002-1221-1601 ${ }^{1}$ \\ kellypinheiros@yahoo.com.br ${ }^{1}$
}

Submetido em 04/04/2015 e aceito em 11/08/2020

\section{RESUMO}

Com a crescente industrialização o homem tem promovido uma série de transformações, tanto ambientais quanto sociais. Mediante a isso, vem sendo estabelecido alguns critérios e normas para criação, implantação e gestão das unidades de conservação no Brasil de forma integrada. Entretanto essas normas e critérios têm provocado uma série de conflitos enfrentados pelos gestores. Estudar sobre percepção ambiental torna-se de extrema relevância um a vez que, visa investigar as relações que uma sociedade tem com o seu ambiente vivencial, buscando entender fatores, mecanismos e processos que levam as pessoas a terem opiniões e atitudes sobre as mudanças neste ambiente.
O estudo teve como objetivo analisar a percepção dos residentes de três comunidades ao entorno do Parque Estadual da Lagoa do Açu, RJ. Para tanto, foram aplicados questionários semiestruturados, em que os resultados apontam para um distanciamento da população local com a implantação do parque, uma vez que a maioria dos entrevistados não conhece o parque e classificam sua implantação como sendo ruim. Desta forma, a articulação entre o poder público e a sociedade civil e a gestão compartilhada seriam formas de minimizar os conflitos, uma vez que pode inserir as comunidades estudadas no processo de gestão do parque.

PALAVRAS-CHAVE: Parque Estadual da Lagoa do Açu, Percepção Ambiental, Unidades de Conservação.

\section{ENVIRONMENTAL PERCEPTION OF THE COMMUNITY THE STATE PARK POND AÇU / RJ}

\begin{abstract}
With increasing industrialization, after the industrial revolution man has promoted a series of transformations, both environmental and social. Through this, it has been established some criteria and standards for the creation, deployment and management of protected areas in Brazil in an integrated manner. However those standards and criteria have caused a number of conflicts faced by managers. In view of these conflicts, and to characterize the socioeconomic profile
\end{abstract}

and the perception of residents to community this process, semi-structured questionnaires were applied in three of the next to the park communities, the results point to a detachment of the local population with the implementation of the park, Since the majority of respondents did not know the park and rate their implementation as bad. Thus, the relationship between the government and civil society and the shared management would be ways to minimize conflicts.

KEYWORDS: Acu State Park Pond , Environmental Perception, Protected Areas 


\section{INTRODUÇÃO}

A partir da revolução industrial no século XVIII, o homem promove uma série de transformações tanto sociais como ambientais, motivando o uso indiscriminado dos recursos naturais, causando transformações significativas no meio ambiente e na sociedade.

No Brasil, país com altíssima biodiversidade, essas transformações ambientais estão sendo freadas com a criação do Sistema Nacional de Unidades de Conservação (SNUC), instituído pela Lei no 9.985, de 18 de Julho de 2000, que estabelece os critérios e normas para criação, implantação e gestão das unidades de conservação de forma integrada, visando, dentre outros objetivos, contribuir para a manutenção e restauração da diversidade biológica dos ecossistemas naturais, promover o desenvolvimento sustentável e proteger paisagens naturais e pouco alteradas de notável beleza cênica (BRASIL, 2000).

Entretanto, um dos principais problemas enfrentados pelos gestores das Unidades de Conservação (UC) é o conflito envolvendo o manejo da área preservada e a população que se encontra no entorno destas unidades (Costa \& Vasconcellos Sobrinho, 2015). Esses conflitos surgem porque cada indivíduo envolvido na UC tem sua percepção e vivência (Costa et al,2018). Sendo maiores onde já existem comunidades consolidadas, como é o caso da Quixaba, Maria da Rosa e Xexé.

O estudo da percepção ambiental é de fundamental importância para compreender melhor a inter-relação entre o homem e o ambiente, suas expectativas, anseios, satisfações, julgamentos e condutas (Ferreira \& Profice ,2019), além de tratar discussões que passam das questões lineares sobre as questões socioambientais (Alves et al, 2017). Por meio, deste é possível saber como a comunidade compreende a região a qual está inserida, seu valores simbólicos e culturais, o que pode favorecer o processo de gestão compartilhada das unidades de conservação, visto que um dos desafios é responder as características sociais do ambiente, ante os conflitos de interesse e as prioridades de cada ator envolvido (Leuzinger, 2016).

A recente criação do Parque Estadual da Lagoa do Açu (PELAG), localizado entre os municípios de São João da Barra e Campos dos Goytacazes, no Estado do Rio de Janeiro, embora represente diversos benefícios ambientais, como proteção à biodiversidade, formação de corredor ecológico, além da melhoria na qualidade de vida da população, pode determinar diversas alterações e transformações socioambientais aos moradores desta área.

Nesta perspectiva, o presente trabalho tem como objetivo analisar a percepção ambiental dos moradores das comunidades da Quixaba, Maria da Rosa e Xexé, em relação às transformações e a implantação do Parque Estadual da Lagoa do Açu. 


\subsection{Histórico das Unidades de Conservação}

As Unidades de Conservação (UC) tiveram seu início nos Estados Unidos da América, com a criação do Parque Nacional de Yellowstone, em 1872, sendo a região considerada segundo Diegues (2001), como berço da formação das áreas de proteção ambiental. Essa criação tem relação com o movimento conhecido como "American Renaissence", no qual a natureza é colocada como marca da nacionalidade americana. Desta forma, o parque que tem $8.991 \mathrm{Km}^{2}$ foi criado por meio de uma política que ficou conhecida como proteção da "wilderness", ou seja, de uma natureza selvagem intocada, vista como santuário da nacionalidade americana.

Para Terborgh (2003) essas estratégias de conservação foram baseadas em aspectos religiosos, cerimoniais e cênicos. Inicialmente, os parques nos Estados Unidos prezavam mais as questões culturais do que ecológicas, sua implantação se deu primeiramente nas montanhas abarcando posteriormente os "canyons" e desertos. A ideia de parques nacionais em áreas dotadas de importantes recursos naturais só adquiriu forças com o passar dos anos (Runte, 2003).Outro parque que merece destaque, neste processo de surgimento das unidades de conservação, é o Parque Nacional "Yosemite", também localizado nos Estados Unidos. A área foi decretada como "inalienável em qualquer tempo"

No Brasil, as UC começaram a ser estabelecidas, por iniciativa do governo federal, a partir de 1937(Brito, 2003). Neste ano foi criado o primeiro parque na divisa entre Minas Gerais e o Rio de Janeiro, o Parque Nacional de Itatiaia. Seguiu-se o estabelecimento de outros Parques, em 1939, o Parque Nacional do Iguaçu, e o Parque Nacional da Serra dos Órgãos, no Rio de Janeiro (Bensusan, 2006). Em 1973, a União Internacional para Conservação da Natureza e dos Recursos Naturais (IUCN) elaborou uma abrangente classificação internacional, baseada em seus objetivos de gestão, que se assemelham as categorias criadas no Brasil, onde são denominadas unidades de conservação (Medeiros, 2006).

Sendo, as Unidades de Conservação Federais gerenciadas pelo Instituto Chico Mendes de Conservação da Biodiversidade (ICMBio) e regidas pelo Sistema Nacional de Unidades de Conservação da Natureza. Este ocupa a quarta maior superfície terrestre coberta por unidades de conservação no mundo, com 1.278 .190 km2 (Medeiros et al., 2011)

Utiliza-se como política ambiental a criação de Áreas Protegidas ou Unidades de Conservação com diferentes extensões e graus de utilização, na tentativa de proteger e gerenciar os elementos significativos dos ecossistemas. Segundo Motta (2005), esses territórios passam a ser controlados pelo Poder Público segundo categorias de manejo determinadas em função do nível de proteção que se espera para cada uma dessas áreas.

Além disso, a população deve ser envolvida nos processos de construção das políticas públicas, da criação das normas e da fiscalização ambiental destas unidades, no qual os usuários de tais recursos, as autoridades competentes, os pesquisadores e qualquer ator interessado somem esforços para o cumprimento dos objetivos pertinentes à criação das unidades mencionadas (Rando et al, 2017). Este envolvimento da população nas ações citadas voltadas ao gerenciamento das áreas protegidas caracteriza uma nova maneira de lidar com a natureza, conhecida como Gestão 
Participativa ou Gestão Compartilhada das mesmas(Riondet-Costa et al,2018), o que permite a expressão dos interesses dos diversos agentes sociais envolvidos ( Andrade \& Lima,2016).

\subsection{Caracterização socioambientais da região ao entorno do Parque Estadual da Lagoa do} Açu

A população que habita essa área e arredores é composta por comunidades rurais, pescadores artesanais, agricultores familiares, posseiros e pequenos comerciantes (Kury, Rezende, Pedlowski, 2010). Além desses, há os habitantes temporários, que frequentam a região na estação de veraneio, atraídos pelas praias locais e pelo clima.

Estudos feitos por Costa (2013) para a caracterização da área demonstram que as áreas alagadas da região apresentam a maior porcentagem de cobertura do solo (44,4\%). Vê-se que grande área do parque também é ocupada por áreas úmidas $(36,6 \%)$, sendo que parte dessas é inundável em épocas de cheias ou chuvosas. A vegetação nativa ocupa aproximadamente $8,0 \% \mathrm{da}$ área do parque. Parte da área de restinga foi retirada para a implantação de loteamentos ou atividades agropecuárias, provocando o surgimento de campos abertos e aumentando a área de campos de areias em algumas partes. O clima é caracterizado como tropical subúmido seco a semiárido, com calor bem distribuído o ano todo e com precipitação pluviométrica média anual variando de 800 a 1.200 mm, apresentando as maiores taxas de precipitação durante os meses de verão, e as menores, nos meses de inverno.

Nesta região há ocorrência endêmica de anfíbios de restinga tais como: perereca de bromélia (Xenohyla truncata), perereca-de capacete (Aparasphenodon brunoi). Entre os répteis endêmicos de restingas fluminenses, pode-se citar o lagarto de cauda-verde (Cnemidophorus littoralis). Ocorrem também espécies como o jabuti de cabeça vermelha (Geochelone carbonaria) e o jacaré do papo amarelo (Caimam latirostris). Das cinco espécies de tartarugas marinhas que desovam no litoral brasileiro, há registro de desova de três delas, todas ameaçadas de extinção: tartarugas cabeçudas (Caretta ceretta), tartaruga- de-couro (Dermochelys coriacea) e a tartarugade-pente (Eretmochelys imbricata) (Bidegain, Mattos, Terra, 2008). Além dessas espécies, um estudo realizado na Lagoa do Açu (Freesz, Novelli, Cordeiro, 2005) registrou 58 espécies de aves, distribuído em 11 ordens, 22 famílias e 54 gêneros, sendo várias migratórias aquáticas da América do Norte.

Além disso, na região é possível encontrar manguezais que se comunicam com a restinga e onde se encontra a maior população de mangue de botão ( Conacarpus erectus) do Estado do Rio de janeiro ( Soffiati,2009).

\subsection{Unidades de Conservação e percepção ambiental}

A implantação de unidades de conservação é uma medida que na maioria das vezes envolve muitos conflitos, dividindo opiniões principalmente quando se trata de unidades de conservação que tenham uma maior restrição, como é o caso dos parques. Constata-se que uma das dificuldades para a proteção dos ambientes naturais está na existência de diferentes percepções dos valores e 
da importância dos mesmos, entre os indivíduos de culturas diferentes ou de grupos socioeconômicos os quais desempenham funções distintas, no plano social, nesses ambientes.

A necessidade de remoção de moradores e outros usuários de áreas destinadas a unidades de conservação de proteção integral geram muitos conflitos pelo uso destes espaços, envolvendo interesses e visões diferenciadas, além de determinar uma mudança na dinâmica social local.

Os processos de gestão e implantação de UC devem considerar a realidade local no intuito de proteger a diversidade biológica e sociocultural (Câmara et al, 2017). Entretanto, tal fato ainda representa um grande desafio, principalmente porque na maioria das vezes há a exigência da exclusão da população em áreas de proteção integral, nas quais a mesma não é considerada parte dos espaços naturais e tampouco lhe é atribuída responsabilidade de cooperar com as práticas necessárias à manutenção da qualidade ambiental destes. Com isso, uma parcela significativa da sociedade é negligenciada e ficando à mercê desta relevante política pública (Silva, 2011).

De acordo com Primack \& Rodrigues (2001) o envolvimento da população local é um elemento importante que precisa ser incorporado nas estratégias de manejo da conservação para que os grupos locais adquiram capacidade de formular e alcançar os seus próprios objetivos de desenvolvimento em conformidade com a preservação. Sendo, uma importante ferramenta, capaz de orientar a formulação de políticas públicas adequadas às necessidades e ansiedades da população (Brito et al, 2016).

Estudos feitos por Santos et al (2019) apontam que o estudo das percepções ambientais e das necessidades dos diferentes atores sociais é de extrema importância para uma gestão ambiental eficaz. Visto que, essa percepção muitas vezes não é algo expresso ou verbalizado pela população (Pradeiczuk etl al, 2015). Segregar áreas naturais da população pode gerar desconforto, todavia se essas áreas protegidas puderem gerar vínculo afetivo com a população, diversos problemas relacionados ao meio ambiente poderão ser solucionados, pois, surgirá o sentido de patrimônio comum, que deve ser desfrutado e conservado por todos.

Apesar da relevância existente na relação homem-natureza, poucos são os trabalhos científicos encontrados sobre este assunto. O Parque Estadual da Lagoa do Açu localizado entre os municípios de Campos dos Goytacazes e São João da Barra, ainda, não possui Plano de Manejo, que constitui um importante instrumento de planejamento e gestão. Diante desse cenário, este trabalho teve como objetivos identificar o perfil socioeconômico e analisar a percepção ambiental de algumas comunidades ao entorno desse parque, a fim de se conhecer os significados e atitudes que regem as relações estabelecidas pela comunidade rural do entorno deste parque com os elementos naturais e a Unidade de Conservação.

Os resultados desse estudo serão fundamentais para subsidiar a elaboração do Plano de Manejo desta UC e para o envolvimento dessa comunidade na conservação e utilização sustentável dos recursos naturais provenientes do parque. 


\section{METODOLOGIA}

Este trabalho apresenta uma característica exploratória e analítica. Além da pesquisa bibliográfica e documental, foi realizada uma pesquisa de campo, com aplicação de questionários semiestruturados, objetivando-se analisar a percepção ambiental da população em relação ao parque bem como o posicionamento da população residente na área do entorno, e entrevistas semiestruturados com diferentes atores sociais. Para realização do estudo, foram utilizados como material de pesquisa, máquina fotográfica, computador, gravador, mapas e os questionários.

Os questionários foram aplicados na população da Quixaba, Xexé, e Maria da Rosa três das localidades afetadas com o Parque Estadual da Lagoa do Açu (Figura1), sendo a estratégia adotada nessa pesquisa a aplicação do questionário com entrevista, de forma a garantir maior flexibilidade nas perguntas e possibilitar o esclarecimento e aprofundamento de algumas questões (Arruda, 2011).

Figura 1- Localização do Parque Estadual da Lagoa do Açu e as comunidades estudadas.

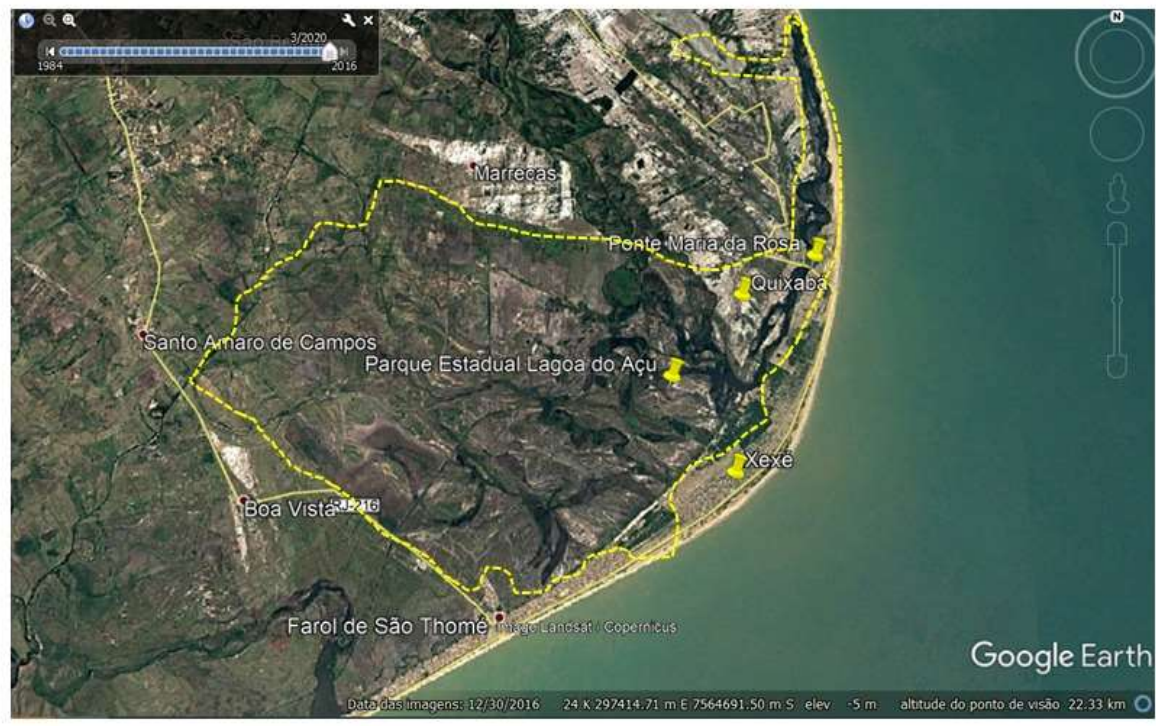

Fonte: Google Earth, 2020

Ressalta-se, ainda, que para a escolha dos entrevistados foi levada em consideração uma amostragem aleatória simples, adotado um nível de confiança de $97 \%$ e uma margem de erro de 7,5\% na obtenção do tamanho da amostra.

A partir da equação (1) apresentada por Agresti e Finlay (2009), foi determinado o número $\mathrm{n}$ de pessoas a serem entrevistadas.

$\mathrm{n}=\pi(1-\pi)\left(\frac{z}{M}\right)^{2}$, onde $\pi$ é a proporção inicialmente adotada como resposta aos questionamentos da pesquisa, z é o valor da distribuição normal associado ao nível de confiança adotado e $M$ é a margem de erro. Para a proporção, foi utilizada uma estimativa de $50 \%$, de modo a garantir uma amostragem mais segura, já que resulta em uma amostra maior, e o z, para o nível de confiança de $97 \%$, é 1,96. Diante da população estimada da Quixaba e Xexé de 850 habitantes, 
conforme apresentado pela agente comunitária das localidades, chega-se ao número de 171 questionários a serem aplicados em cada comunidade. A quantidade de moradores da comunidade da Maria da Rosa não foi possível ser estimada, visto que os dados não estão registrados no IBGE e nem com agentes de saúde, sendo aplicados dessa forma 30 questionários. Inicialmente, foi elaborado um questionário piloto com caráter qualitativo, de forma a identificar as alterações necessárias a serem feitas para se obter uma versão definitiva.

Dessa forma, foram elaboradas três versões do questionário, em que foram acrescentadas algumas questões que, a partir das respostas do questionário piloto, percebeu-se serem temáticas que necessitavam de maior aprofundamento, e retiradas outras que já estavam contempladas na resposta de perguntas anteriores. A cada versão, foi realizado um teste de aplicação com a população visando à adequação às novas necessidades da pesquisa. O questionário deixou, então, de ser unicamente qualitativo e passou a ser predominantemente quantitativo com o intuito de facilitar a tabulação dos resultados, que foram sistematizados em um Banco de Dados no software Microsoft Excel 2010, para na sequência serem tratados e analisados descritivamente.

\section{RESULTADOS E DISCUSSÕES}

Para esta publicação serão apresentadas e discutidas algumas questões importantes e pertinentes ao tema percepção ambiental, visando perceber como os moradores estão lidando com o processo de mudanças decorrentes da implantação do PELAG. Dentre as questões abordadas estão à importância da implantação do parque e a utilização das lagoas, as quais fazem parte da Unidade de Conservação.

Por meio das entrevistas pode-se constatar que mais de $50 \%$ da população das três comunidades entrevistadas não conhecem o Parque Estadual da Lagoa do Açu (figura 2), sendo que na localidade da Maria da Rosa esse quantitativo chega à 70\%. Dados semelhantes sobre a implantação do PELAG foram apresentados por Silva \& Rangel (2014), ao estudarem a comunidade de Alto Cordeiro, RJ, onde a maioria da população não sabia do que se tratava o parque.

Figura 2 : Conhecimento da população sobre o parque.

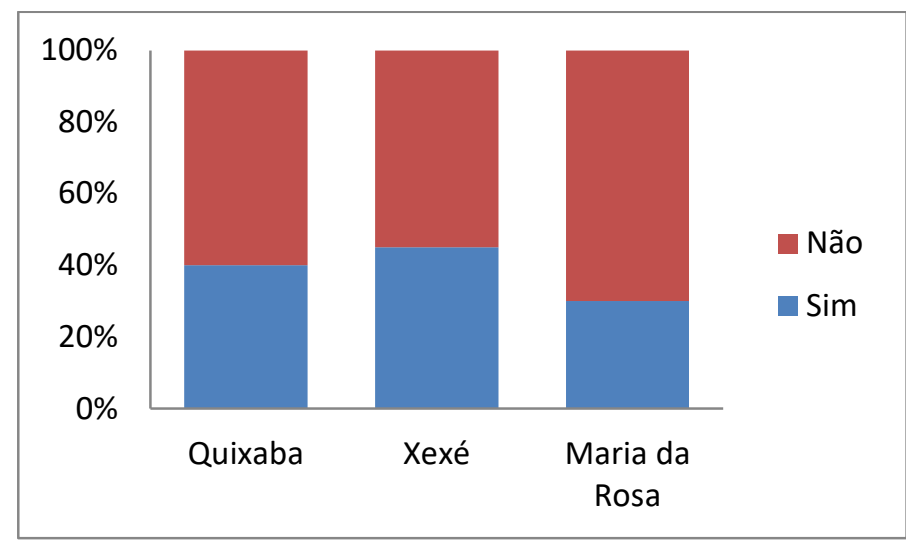

Fonte: Kelly Pinheiro dos Santos 
O fato de não conhecerem o parque acaba fazendo com que sua implantação, seja considerada como ruim para $50 \%$ da população (figura 3). Tal fato pode ser justificado, pois a criação de uma área de proteção integral restringe alguns usos. Em estudos feitos por Botelho (2009), no Parque Estadual de Três Picos foi possível constatar que os moradores que viviam ao entorno do parque entenderam a criação do Parque como um cerceamento de seu direito sobre o território. Além disso, a exclusão da população no manejo do parque pode provocar uma rejeição destes com a UC. Cabe salientar que, durante as entrevistas foi possível observar que as pessoas que disseram conhecer o parque, não sabem que regiões ele abrange. O que mostra que a comunidade local ainda desconhece a importância da implantação de uma Unidade de Conservação, caracterizando um nível baixo de comunicação entre a comunidade local e os gestores do parque. Alguns estudos afirmam que fatores como transparência e acesso à informação caracterizam-se como parte relevante do processo de mobilização e engajamento da população nas ações desenvolvidas pela gestão do parque.

Figura 3 : Aceitação da população com a implantação do parque.

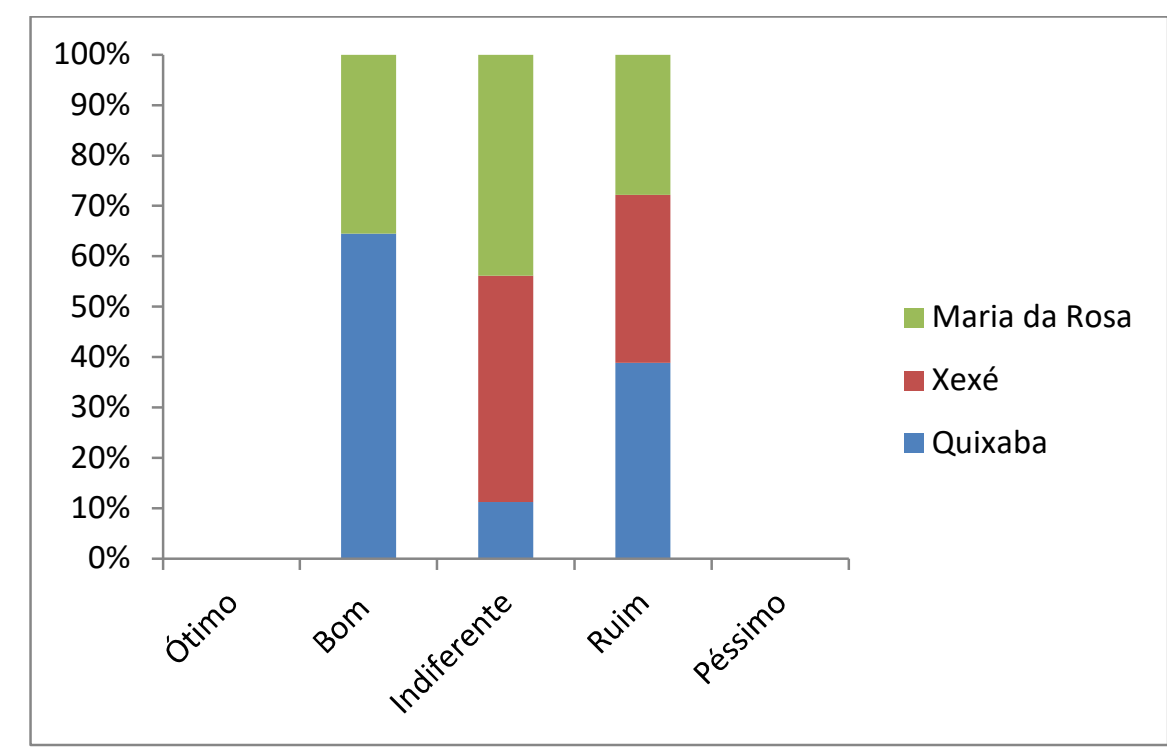

Fonte: Kelly Pinheiro dos Santos

Quando questionados se a comunidade foi comunicada a participar da criação do parque (figura 4), observa-se que para 70\% dos moradores da Maria da Rosa, $80 \%$ dos de Xexé e $85 \%$ dos da Quixabá isso não aconteceu. Estudos feitos por Silva et al 2009, relatam que as comunidades do entorno das UC, se não participam do processo de criação e gestão desta, podem desenvolver um posicionamento contrário à implantação. Visto que, é preciso inserir a comunidade nas atividades do parque a fim de minimizar os possíveis conflitos ambientais existentes. De acordo com Rando (2017) uma gestão adequada são estratégias globalmente reconhecidas do modo tradicional de vida de diversas populações e dos respectivos direitos para preservação e conservação da biodiversidade. 
Figura 4 : População comunicada a participar da criação do parque.

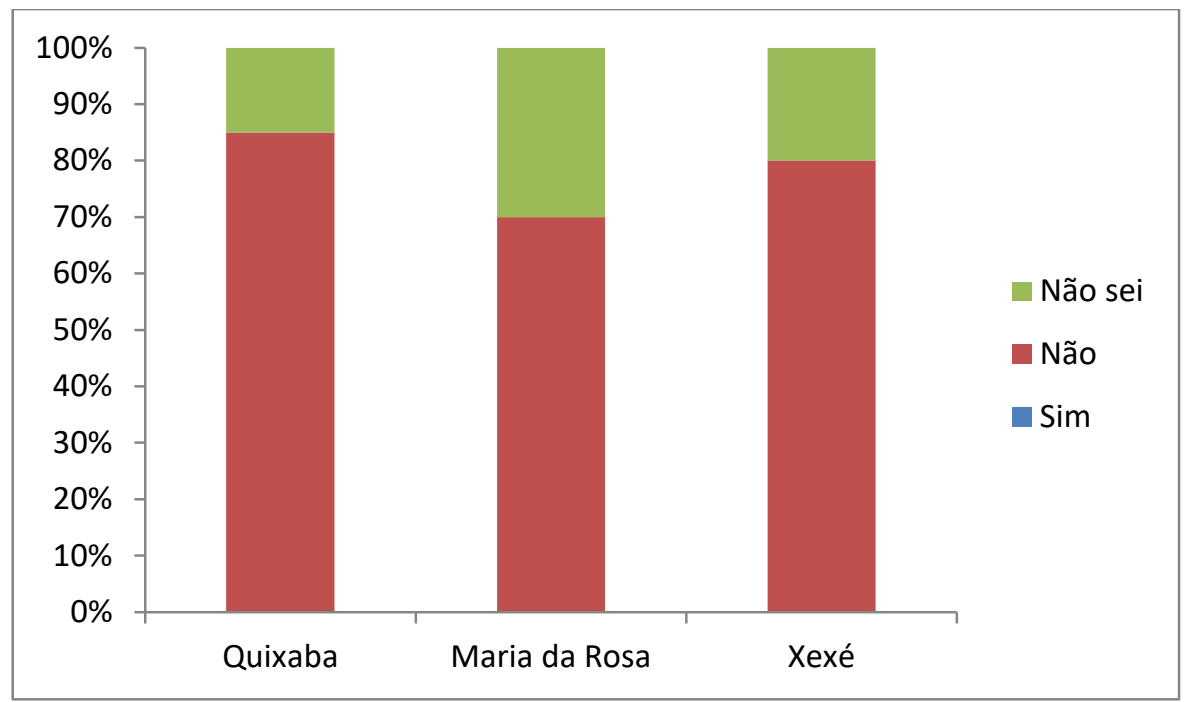

Fonte: Kelly Pinheiro dos Santos

De acordo com mais de 70\% da população da Quixaba é importante que a comunidade esteja envolvida com a gestão do parque (figura 5). Um dos moradores ressalta que ninguém conhece melhor a região do que a própria comunidade, logo incluir essa população em algum trabalho do parque é de extrema relevância. O descompasso entre a população local e os órgãos gestores só aumentam as lacunas existentes, o que irá afetar diretamente nas possíveis diretrizes para elaboração do plano de manejo do parque. Tais diretrizes devem ser elaboradas, sobretudo ao se avaliar a cultura institucional e a percepção coletiva, para que se adote estratégias que resultem maior eficácia na implantação das políticas no cenário real e maior efetividade no processo de educação ambiental junto ao público participante. Consoante a isto a falta de comunicação existente e de um processo que seja democrático, provoca uma percepção "negativa" sobre as UCs pela comunidade.

Figura 5 : Importância da população está envolvida na gestão do parque.

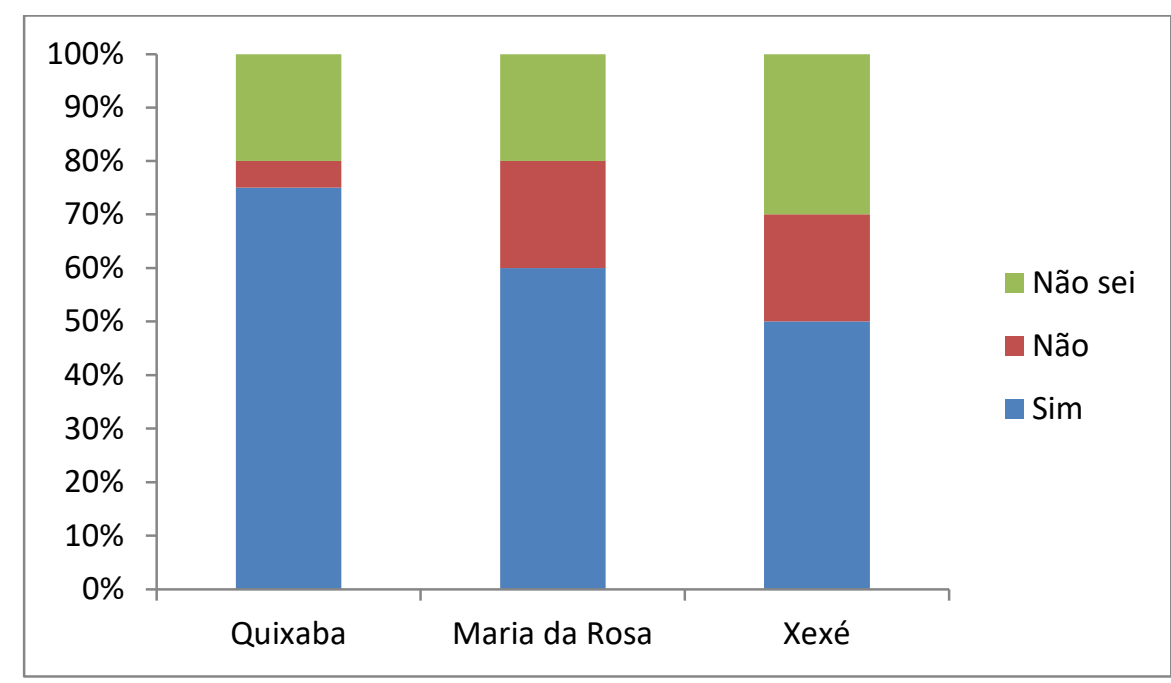

Fonte: Kelly Pinheiro dos Santos 
Estudos feitos por Salinas (2005) demonstram que áreas naturais protegidas devem ser manejadas com a participação ativa da população habitante circunvizinha e usuária. Porém, 90\% dos moradores relatam desconhecer pessoas da comunidade que estejam trabalhando, ou seja, no processo de gestão do parque (figura 6). Acrescentam ainda, que os que trabalham no parque residem em outros municípios, o que evidencia o distanciamento entre a gestão do parque e as comunidades locais acentuando a ausência de participação dos morados no processo de criação e gestão das UC.

Figura 6 : Participação da comunidade na gestão do parque.

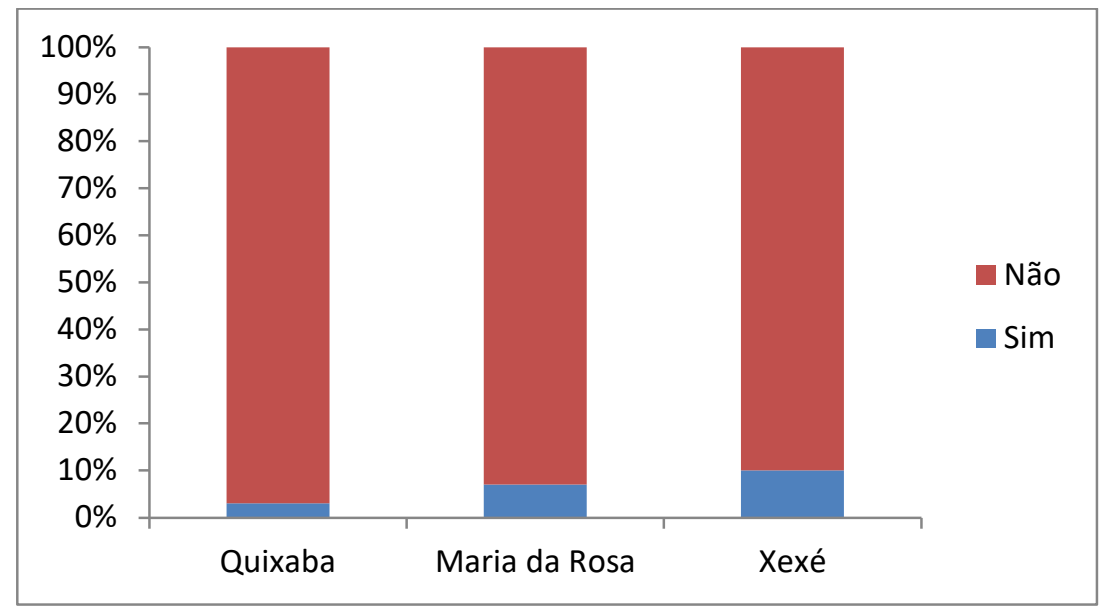

Fonte: Kelly Pinheiro dos Santos

Visando perceber a relação da população com as lagoas existentes na região e assim diagnosticar a importância ambiental, por meio dos questionários foi possível inferir que nas comunidades da Quixaba, Maria da Rosa e Xexé, respectivamente $80 \%$, 67\% e 75\% da população consideram as lagoas da região importantes (figura 7).

Figura 7 : Importância das lagoas para a comunidade.

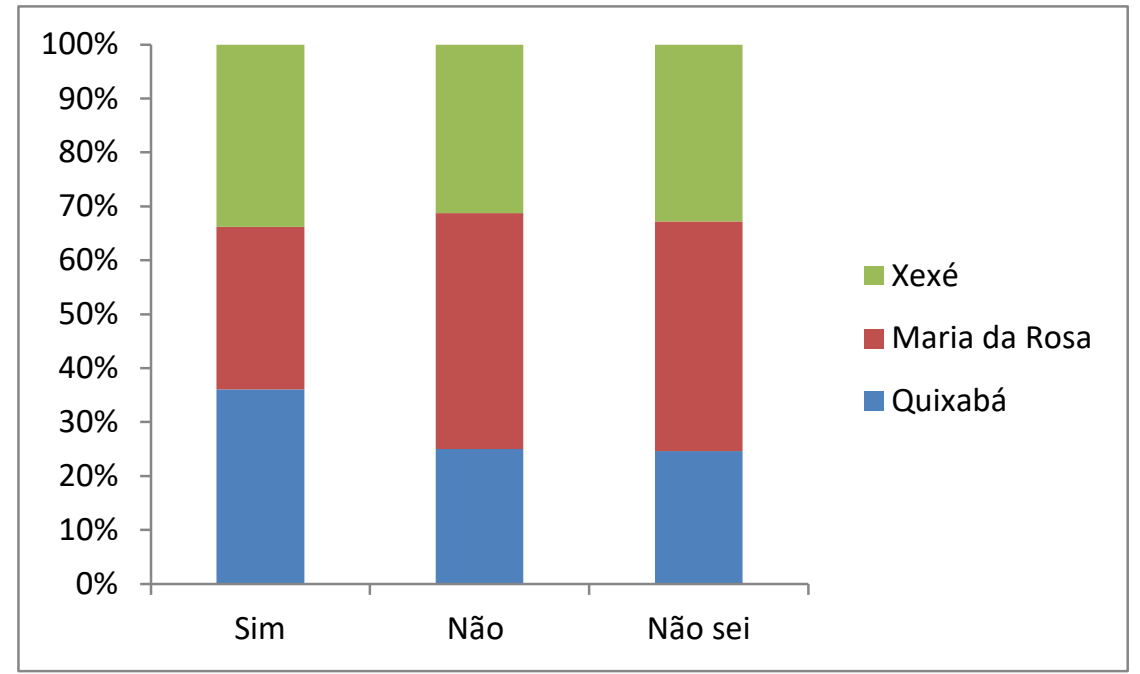

Fonte: Kelly Pinheiro dos Santos 
Sendo utilizada principalmente para pesca, extração de taboa, agricultura e lazer (figura 8). Ressaltam que a lagoa tem acima de tudo importância econômica e sentimental, pois, além de ser fonte de renda é local de recreação com a família. O ambiente em questão não é apenas o espaço natural, mas o resultado de interações múltiplas e complexas, as quais permitem a construção de sentido de localidade, territorialidade, pertencimento, identidade e contextualização para os diferentes agentes sociais envolvidos. Desta forma, a identidade territorial, de fato, é antes de tudo um produto cognitivo, que resulta de um processo de análise e de representação que nos permite elucidar um determinado âmbito espacial do próprio entorno. Consoante a isso, a percepção ambiental que os moradores possuem sobre a lagoa, possibilita a tomada de consciência do ambiente pelo homem, a partir do meio em que ele está inserido, sendo possível a caracterização do tipo de relação estabelecida entre as comunidades e a natureza (Ferreira \& Profice,2019).

Figura 8 : Utilização das lagoas pela comunidade.

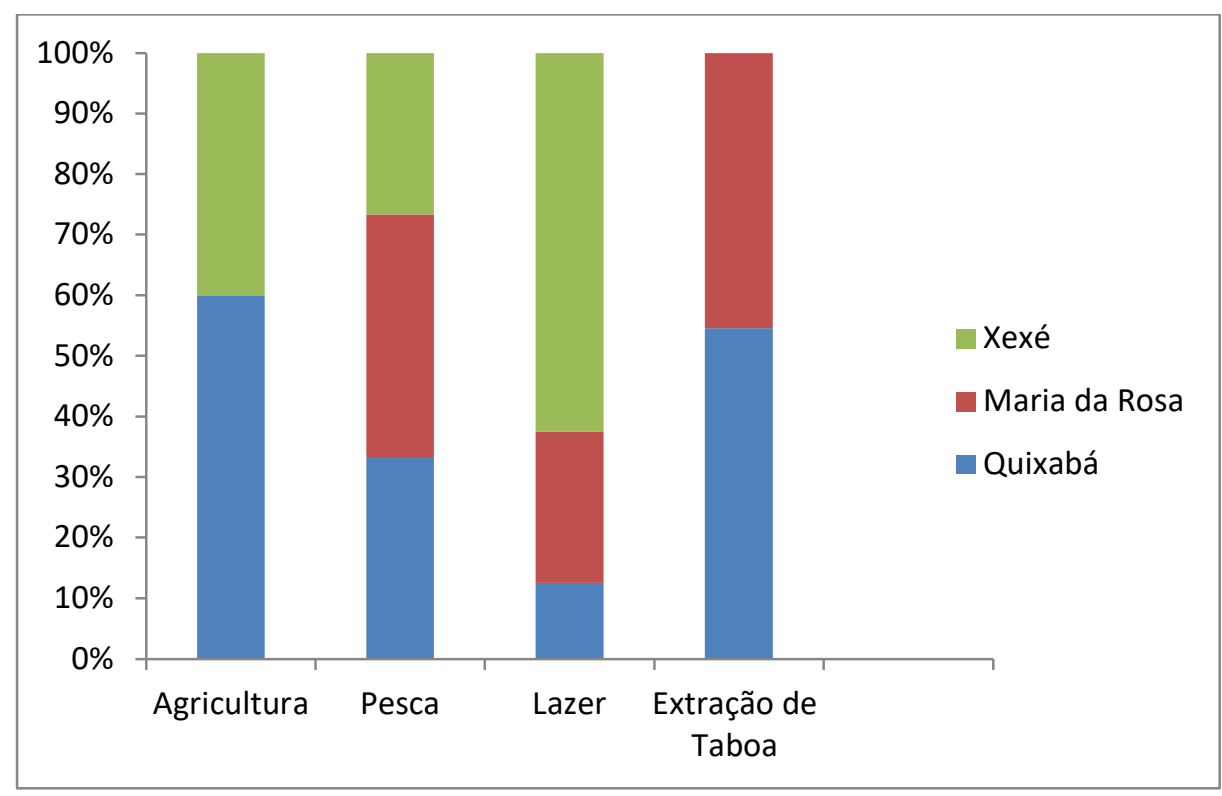

Fonte: Kelly Pinheiro dos Santos

Para além do recurso natural, a lagoa abarca dimensões simbólicas, reveladora de significados, valores, crenças, mitos e utopias materializados na forma de paisagens. Os estudos de percepção ambiental indicam a existência de múltiplas interpretações para uma paisagem humanamente percebida, a qual é carregada de conteúdos racionalizados, mas também relativos a representação e ao universo simbólico-cultural que constitui a base para consciência humana sobre a vida, o meio ambiente e o mundo.

Ao serem inquiridos se o parque está gerando mudanças, mais de $60 \%$ de dos entrevistados nas três comunidades afirmam que houve mudanças, como apresentado na figura 9, em conversam com estes moradores muitos afirmaram que essa mudanças podem acarretar conflitos em diversas áreas. De acordo com eles esses conflitos podem ser principalmente por causa da proibição da pesca e da extração da vegetal (aroeira e taboa), visto que para muitos essas atividades são fontes de renda. 
Figura 9 : Mudanças ocorridas com a implantação do parque.

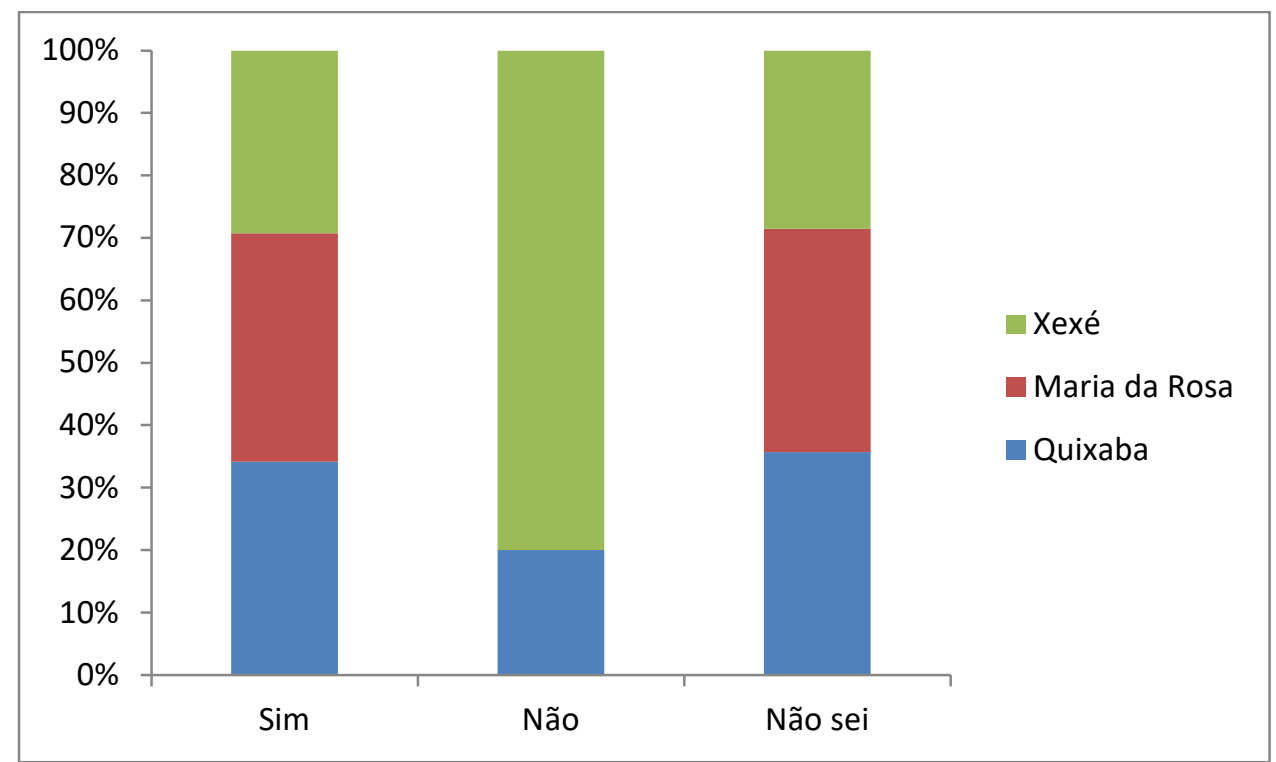

Fonte: Kelly Pinheiro dos Santos

Diante do exposto, percebe-se a importância da realização dos questionários, não só para diagnosticar os problemas identificados pela população, mas também para perceber o grau de satisfação e insatisfação da mesma em relação à implantação do parque. De acordo com Santos et al (2019, estudos sobre a percepção ambiental permitem conhecer melhor o público relacionado à UC, uma vez que identifica o valor e a importância das áreas para os diversos grupos que ali residem. Isto contribui para o planejamento e manejo adequado feito pelos gestores.

\section{CONCLUSÕES}

De acordo com os resultados obtidos nesta pesquisa pode-se inferir que a maioria da população não conhece o Parque Estadual da Lagoa do Açu, considerando sua implantação como sendo desagradável. Observa-se que estes não foram comunicados a participar da criação do parque, considerando importante o envolvimento no processo de gestão do mesmo e que as lagoas da região possuem grande importância sendo utilizadas para pesca e extração de taboa em Maria da Rosa e Quixaba e para lazer em Maria da Rosa.

Desta forma, ressalta-se que o presente trabalho deve ser o início de estudos à respeito da comunidade locais, para que sejam identificados os valores e importância dos ecossistemas para população para assim serem incluídas no plano de manejo. 


\section{REFERÊNCIAS BIBLIOGRÁFICAS}

Agresti, A.; Finlay, B. (2009). Statistical Methods for the Social Sciences. Pearson/Prentice Hall.

Alves,D.C.; Sampaio,A.V.O.; Sampaio,V.S. Percepção ambiental de Unidades de Conservação: Estudo sobre as Lagoas das Bateias e do Jurema em Vitória da Conquista ( BA). Revista Geopauta, V .01, n.03,2017.

Andrade, F.A.; LIMA, V. T. A. (2016, jul-dez). Gestão participativa em unidades de conservação: uma abordagem teórica sobre a atuação dos conselhos gestores e participação comunitária. RELEM - Revista Eletrônica Mutações.

Arruda, D. (2011, jul./dez.). A política regional no Brasil: Uma análise dos planos para o partir da visão sistêmica. Revista Cadernos do Desenvolvimento. Rio de Janeiro, v.6 n. 9, p. 61-91.

Bensusan, N. (2006). Conservação da biodiversidade em áreas protegidas. Rio de Janeiro: FGV.

Bidegain, P. (2002). Lagoas do Norte Fluminense: perfil ambiental. Rio de Janeiro: Fundação Superintendência de Rios e Lagoas (SERLA). 148 p. (Boletim, 14).

Bidegain, P.; Mattos, J.; Terra; T. (2008). Estudo Técnico Para Criação de Parque Estadual Para Proteção das Restingas de Grussaí e lquipari e da Lagoa Salgada. Superintendência de Biodiversidade da Secretaria de Estado do Ambiente/ Instituto Estadual de Florestas - IEF, Rio de Janeiro.

Botelho, E.S. (2009). Conflitos na gestão de parques: O caso do conselho do Parque Estadual de Três Picos, RJ. Dissertação de mestrado. Instituto de Psicologia. Universidade Federal do Rio de Janeiro, RJ.

Brasil. Lei no 9.985, de 18 de Julho de 2000. Institui o Sistema Nacional de Unidades de Conservação da Natureza. Brasília.

Brito, M.C.W. (2003). Unidades de conservação: intenções e resultados. 2ª ed. São Paulo: Ed. Annablume.

Brito, E. N., Régis, M. M., Lamano-Ferreira, A. P. N. (2016). Perfil e percepção ambiental de frequentadores do Parque do Guarapiranga - São Paulo/SP. Revista Científica ANAP Brasil, $9(14)$.

Câmara, E.S., Andriolli,C., VIEIRA,L. (2017). Vozes do campo e áreas protegidas:a percepção ambiental de pequenos proprietáriosrurais sobre os recursos naturais. Revista: Estudos, Sociedade e Agricultura. v. 25 n. 3.

Costa, M.B. (2013). Uso cobertura do solo do Parque Estadual da Lagoa do Açu. Dissertação( mestrado). Instituto Federal Fluminense, RJ. 
Costa, E.R. (2018, dez.). Vasconcellos Sobrinho, M.;Rocha,G.M. Conflitos socioambientais e perspectivas de governança em Unidades de Conservação: o caso da Floresta Estadual do Amapá, Amazônia, Brasil. Revista Desenvolvimento e Meio Ambiente, v. 49, p. 83-107.

Costa, E. R.; Vasconcellos Sobrinho, M. (2015). Unidades de Conflitos socioambientais e perspectivas de governança em Unidades de Conservação de Uso Sustentável e Agricultura Familiar na Amazônia: conflitos e desafios na Floresta Estadual do Amapá. Revista GeoAmazônia. 3(5), 97116.

Diegues, A.C. (2000). $O$ mito moderno da natureza intocada. São Paulo: Ed. Hucitec.

Freesz, N. P.; Novelli, R.; Cordeiro, Jr., L. S. A. (2005). Dinâmica da Avifauna da Lagoa do Açu, Norte Fluminense, RJ. In: VII Congresso de Ecologia do Brasil, 2005, Anais eletrônicos Caxambu. Disponível em: <http://www.seb-ecologia.org.br/viiceb/resumos/175a.pdf>. Acesso em: 05/08/2020.

Ferreira, D.J., Profice,C.C. (2019, set.-dez.). Percepção ambiental de Unidades de Conservação: 0 olhar da comunidade rural de Barrocão no Entorno do Parque Estadual da Serra do ConduruBA. Revista Fronteiras:JournalofSocial,TechnologicalandEnvironmentalScience. v.8,n.3.

Leuzinger,M.D. (2016, jul/set). A gestão compartilhada de áreas protegidas como instrumento de compatibilização de direitos. Revista de informação legislativa: RIL, v.53,n.2011,p253-27,1.

Medeiros, R. (2006, jan./jun). Evolução das tipologias e categorias de áreas protegidas no Brasil. Revista Ambiente\& Sociedade, vol. IX no. 1.

Motta, K. U. (2005). Uma Análise Sobre O Processo De elaboração do Plano de Manejo da Área de Proteção Ambiental de Guaratuba Trabalho de Conclusão de Curso apresentado ao Curso de Engenharia Ambiental do Centro de Ciências Exatas e de Tecnologia da Pontifícia Universidade Católica do Paraná. Curitiba, 49 p.

Neiman, Z., Patrício, R. F. (2010). Ecoturismo e conservação dos recursos naturais. In: Neiman, Zysman; Rabinovicci, Andrea. Turismo e meio ambiente no Brasil. Barueri, SP: Manole, p.84104.

Pradeiczuk, A., Renk, A., Danieli.M.A. (2015). PERCEPÇÃO AMBIENTAL NO ENTORNO DA UNIDADE DE CONSERVAÇÃO PARQUE ESTADUAL DAS ARAUCÁRIAS. REVISTA GRIFOS - N. 38/39.

Primack,R. B. \& Rodrigues, R. (2001). Biologia da Conservação. Londrina: Midiograf. 327p

Rando, A.S., Maranho, A.S, Scarcello, M. (2017, jan./mar.). Gestão compartilhada no Parque Nacional da Serra do Divisor [Acre]: desafios e oportunidades. Revista Labor \& Engenho, Campinas [SP] Brasil, v.11, n.1, p.05-17.

Riondet-Costa,D.R.T.; Botezelli, L.; Farias,O.L.M.; Dupas,L.A. (2018, out/dez.). ANÁLISE DA PARTICIPAÇÃO SOCIAL EM CONSELHOS DE UNIDADES DE CONSERVAÇÃO EM PAÍSES DA 
AMÉRICA DO SUL. Revista Gestão \& Sustentabilidade Ambiental, Florianópolis, v. 7, n. 4, p. 6687.

Salinas, M. F. P. (2005). La participación en el manejo de áreas naturales protegidas. Cuernavaca, Morelos: Universidad Autônoma de México.

Santos, T.B.; Nascimento, A.P.B., Regis,M.M. (2019, mai/ago). Áreas verdes e qualidade de vida: uso e percepção ambiental de um parque urbano na cidade de São Paulo, Brasil. Revista de Gestão Ambiental \& Sustentabilidade 8(2), p. 363-388

Silva, I. R., Rangel, T. A. (2014). Impactos sociais, econômicos, culturais e ambientais provocados pela implantação do CLIPA e PELAG na comunidade de Alto Cardeiro, município de São João da Barra/RJ. Monografia (graduação em geografia). Instituto Federal Fluminense, RJ..

Silva, T. S. da; Cândido, G. A.; Freire, E. M. X. (2009). Conceitos, percepções e estratégias paraconservação de uma Estação Ecológica da caatinga nordestina por populações do seu entorno. Revista Sociedade e natureza 21 (2): 23-37.

Soffiati, A. (2009). Os manguezais do sul do Espírito Santo e do norte do Rio de Janeiro. Campos dos Goytacazes: Essentia Editora.

Terbogh, J. (2003). A Arca de Noé ou porque precisamos de Parques. In:. Fundação o Boticário de Proteção a Natureza. Revista Natureza \& Conservação. Curitiba, V. 1, n. 2, p.9-15.

\section{COMO CITAR ESTE ARTIGO:}

Santos, K.P.dos., E V.P.S.de. (2020). Percepção ambiental das comunidades ao entorno do parque estadual da lagoa do Açu/RJ. Holos. 36(6), 1-16.

\section{SOBRE OS AUTORES}

\section{K.P.DOS SANTOS}

Graduada em Ciências biológicas pela Universidade Federal Fluminense e licenciada em biologia pela Universidade Salgado de Oliveira. Pós- graduada em Educacação ambiental pela Faculdade do Noroeste de Minas; Mestra em Engenharia ambiental pelo Instituto Federal Fluminense. Doutoranda em Ciências Ambientais e Conservação pela Universidade Federal do Rio de Janeiro. E-mail: kellypinheiros@yahoo.com.br

ORCID ID: https://orcid.org/0000-0002-1221-1601

\section{E V.P.S.DE OLIVEIRA}

Doutor em Engenharia Agrícola pela Universidade Federal de Viçosa/UFV. Professor do Instituto Federal Fluminense/IFF. E-mail: vsantos@iff.edu.br ORCID ID: http://orcid.org/0000-0002-5981-0345

Editor(a) Responsável: Francinaide de Lima Silva Nascimento Pareceristas Ad Hoc: JOÃO AMORIM E REGIANE COSTA 


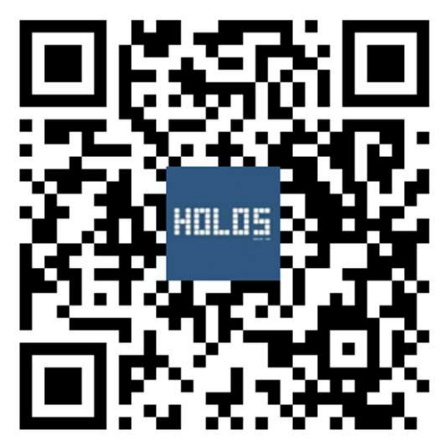

